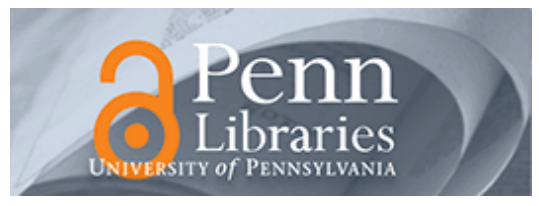

University of Pennsylvania ScholarlyCommons

$5-2007$

\title{
Accounting Information, Disclosure, and the Cost of Capital
}

Richard A. Lambert

University of Pennsylvania

Christian Leuz

Robert E. Verrecchia

University of Pennsylvania

Follow this and additional works at: https://repository.upenn.edu/accounting_papers

Part of the Accounting Commons

\section{Recommended Citation}

Lambert, R. A., Leuz, C., \& Verrecchia, R. E. (2007). Accounting Information, Disclosure, and the Cost of Capital. Journal of Accounting Research, 45 (2), 385-420. http://dx.doi.org/10.1111/

j.1475-679X.2007.00238.x

This paper is posted at ScholarlyCommons. https://repository.upenn.edu/accounting_papers/59

For more information, please contact repository@pobox.upenn.edu. 


\title{
Accounting Information, Disclosure, and the Cost of Capital
}

\author{
Abstract

\section{Keywords} \\ cost of capital, disclosure, information risk, asset pricing \\ Disciplines \\ Accounting
}

In this paper we examine whether and how accounting information about a firm manifests in its cost of capital, despite the forces of diversification. We build a model that is consistent with the Capital Asset Pricing Model and explicitly allows for multiple securities whose cash flows are correlated. We demonstrate that the quality of accounting information can influence the cost of capital, both directly and indirectly. The direct effect occurs because higher quality disclosures affect the firm's assessed covariances with other firms' cash flows, which is nondiversifiable. The indirect effect occurs because higher quality disclosures affect a firm's real decisions, which likely changes the firm's ratio of the expected future cash flows to the covariance of these cash flows with the sum of all the cash flows in the market. We show that this effect can go in either direction, but also derive conditions under which an increase in information quality leads to an unambiguous decline in the cost of capital. 


\title{
Accounting Information, Disclosure, and the Cost of Capital
}

\author{
Richard Lambert* \\ The Wharton School \\ University of Pennsylvania \\ Christian Leuz \\ The Wharton School \\ University of Pennsylvania \\ Robert E. Verrecchia \\ The Wharton School \\ University of Pennsylvania
}

September 2005

Revised, March 2006

\begin{abstract}
In this paper we examine whether and how accounting information about a firm manifests in its cost of capital, despite the forces of diversification. We build a model that is consistent with the CAPM and explicitly allows for multiple securities whose cash flows are correlated. We demonstrate that the quality of accounting information can influence the cost of capital, both directly and indirectly. The direct effect occurs because higher quality disclosures reduce the firm's assessed covariances with other firms' cash flows, which is non-diversifiable. The indirect effect occurs because higher quality disclosures affect a firm's real decisions, which likely changes the firm's ratio of the expected future cash flows to the covariance of these cash flows with the sum of all the cash flows in the market. We show that this effect can go in either direction, but also derive conditions under which an increase in information quality leads to an unambiguous decline the cost of capital.
\end{abstract}

JEL classification: G12, G14, G31, M41

Key Words: $\quad$ Cost of capital, Disclosure, Information risk, Asset pricing

*Corresponding Author. We thank the seminar participants at Ohio State University and an anonymous referee for their helpful comments. 


\section{Introduction}

The link between accounting information and the cost of capital of firms is one of the most fundamental issues in accounting. Standard setters frequently refer to it. For example, Arthur Levitt (1998), the former chairman of the Securities and Exchange Commission, suggests that "high quality accounting standards [...] reduce capital costs." Similarly, Neel Foster (2003), a former member of the Financial Accounting Standards Board (FASB) claims that "More information always equates to less uncertainty, and [...] people pay more for certainty. In the context of financial information, the end result is that better disclosure results in a lower cost of capital.” While these claims have intuitive appeal, there is surprisingly little theoretical work on the hypothesized link.

In particular, it is unclear to what extent accounting information or firm disclosures reduce non-diversifiable risks in economies with multiple securities. Asset pricing models, such as the Capital Asset Pricing Model (CAPM), and portfolio theory emphasize the importance of distinguishing between risks that are diversifiable and those that are not. Thus, the challenge for accounting researchers is to demonstrate whether and how firms’ accounting information manifests in their cost of capital, despite the forces of diversification.

This paper explores both of these questions. We define the cost of capital as the expected return on a firm's stock. This definition is consistent with standard asset pricing models in finance (e.g., Fama and Miller, 1972, p. 303), as well as numerous studies in accounting that use discounted cash flow or abnormal earnings models to infer firms’ cost of capital (e.g., Botosan, 1997; Gebhardt et al., 2001). ${ }^{1}$ In our model, we explicitly allow for multiple firms whose cash flows are correlated. In contrast, most analytical models in accounting examine the role of

\footnotetext{
${ }^{1}$ We also discuss the impact of information on price, as the latter is sometimes used as a measure of cost of capital. See, e.g., Easley and O’Hara (2004) and Hughes et al. (2005).
} 
information in single-firm settings (see Verrecchia, 2001, for a survey). While this literature yields many useful insights, its applicability to cost of capital issues is limited. In single-firm settings, firm-specific variance is priced because there are no alternative securities that allow investors to diversify idiosyncratic risks.

We begin with a model of a multi-security economy that is consistent with the CAPM. We then recast the CAPM, which is expressed in terms of returns, into a more easily interpreted formulation that is expressed in terms of the expected values and covariances of future cash flows. We show that the ratio of the expected future cash flow to the covariance of the firm's cash flow with the sum of all cash flows in the market is a key determinant of the cost of capital. We demonstrate that accounting information influences a firm's cost of capital in two ways: 1) direct effects - where higher quality accounting information does not affect cash flows per se, but affects the market participants' assessments of the distribution of future cash flows; and 2) indirect effects - where higher quality accounting information affects a firm's real decisions, which influences its expected value and covariances of firm cash flows.

In the first category, we show (not surprisingly) that higher quality information reduces the assessed variance of a firm's cash flows. Analogous to the spirit of the CAPM, however, we show this effect is diversifiable in a "large economy.” We discuss what the concept of "diversification" means, and show that an economically sensible definition requires more than simply examining what happens when the number of securities in the economy becomes large.

More surprisingly, we demonstrate that an increase in the quality of a firm's disclosure about its own future cash flows has a direct effect on the assessed covariances with other firms' cash flows. This result builds on and extends the work on "estimation risk" in finance. ${ }^{2}$ In this literature, information signals are typically modeled as arising from a historical time-series of

\footnotetext{
${ }^{2}$ See Brown (1979), Barry and Brown (1984 and 1985), Coles and Loewenstein (1988), and Coles et al. (1995).
} 
return observations. In particular, Barry and Brown (1985) and Coles et al. (1995) compare two information environments: in one environment the same amount of information (e.g., the same historical time-series) is available for all firms in the economy, whereas in the other information environment there are more observations for one group of firms than another. They find that the betas of the "high information" securities are lower than they would be in the equal information case. They cannot unambiguously sign, however, the difference in betas for the "low information” securities in the unequal- versus equal-information environments. Moreover, these studies do not address the question of how an individual firm's disclosures can influence its cost of capital within an unequal information environment.

Rather than restricting attention to signals that are historical observations of returns, our paper uses a more conventional information-economics approach in which information signals are related to realized or future cash flows. With this approach, we allow for more general changes in the information environment, and we are able to prove much stronger results. In particular, we show that higher quality accounting information and disclosures affect the assessed covariances with other firms, and this effect unambiguously moves a firm's cost of capital closer to the risk-free rate. Moreover, this effect is not diversifiable because it is present for each of the firm's covariance terms and hence does not disappear in "large economies."

Next, we discuss the effects of disclosure regulation on the cost of capital of firms. Using our framework, it is straightforward to show that increasing the quality of mandated disclosures also reduces the cost of capital for firms. In addition to the effect of an individual firm's disclosures, there is an externality from the disclosures of other firms. We also argue that the magnitude of the effect of mandated disclosure on cost of capital will be unequal across firms. Moreover, the reduction in the assessed covariances between firms and the market will not 
always result in a decrease in the beta coefficient of each firm. After all, regardless of the structure of information in the economy, the average beta across firms has to be 1.0. Therefore, even though firms' cost of capital will decline through improved mandated disclosure, their beta coefficients need not.

In the "indirect effect" category, we show that the quality of accounting information influences a firm's cost of capital through its effect on a firm's real decisions. First, we demonstrate that if better information reduces the amount of firm cash flows that managers appropriate for themselves, the improvements in disclosure not only increase price, but in general also reduce firms' cost of capital. Second, we allow information quality to change a firm's real decisions, e.g., with respect to production or investment. In this case, information quality changes the ratio of expected cash flow to non-diversifiable covariance risk and hence influences a firm's cost of capital. We derive conditions under which an increase in information quality results in an unambiguous decrease in a firm's cost of capital.

Our paper makes several contributions. First, we extend and generalize prior work on estimation risk. We show that information quality directly influences firms' cost of capital and that improvements in information quality unambiguously reduce non-diversifiable risks. This finding is important as it suggests that a firm's beta factor is a function of its information quality and disclosures. In this sense, our study provides theoretical guidance to empirical studies that examine the link between firms' disclosures and/or information quality, and firms' cost of capital (e.g., Botosan, 1997; Botosan and Plumlee, 2002; Francis et al., 2004). ${ }^{3}$ It is important to recognize, however, that our information effects are fully captured by an appropriately specified, forward-looking beta. Thus, our model does not provide support for an additional "information

\footnotetext{
${ }^{3}$ In addition, our study provides an explanation for empirical studies that find differences in disclosure regulation can explain differences in firms' equity risk premium (or the average cost of equity capital) across countries (e.g., Hail and Leuz, 2006).
} 
risk” factor. One way to justify the inclusion of information proxies in a cost of capital model would be to note that an estimate of beta, which for instance is based on historical data alone, does generally not capture all information effects. In this case, however, it is incumbent on accounting researchers to carefully specify a "measurement error” model justifying the inclusion of information proxies in the empirical specification. ${ }^{4}$

A second contribution of our paper is that it provides a direct link between information quality and firms' cost of capital, without reference to market liquidity. Prior work suggests an indirect link between disclosure and firms’ cost of capital based on market liquidity and adverse selection in secondary markets (e.g., Diamond and Verrecchia, 1991; Baiman and Verrecchia, 1996; Easley and O’Hara, 2004). These studies, however, analyze settings with a single firm (or settings where cash flows across firms are uncorrelated). Thus, it is unclear whether the effects demonstrated in these studies survive the forces of diversification and extend to more general multi-security settings. We emphasize, however, that we do not dispute the possible role of market liquidity for firms’ cost of capital, as several empirical studies suggest (e.g., Amihud and Mendelson, 1986; Chordia et al., 2001; Easley et al., 2002; Pastor and Stambaugh, 2003). Our paper focuses on an alternative (and possibly more direct) explanation as to how information quality influences non-diversifiable risks.

Finally, our paper contributes to the literature by showing that information quality has indirect effects on real decisions, which in turn manifest in firms' cost of capital. In this sense, our study relates to work on real effects of accounting information (e.g., Kanodia et al., 2000 and 2004). These studies, however, do not analyze the effects on firms’ cost of capital or nondiversifiable risks.

\footnotetext{
${ }^{4}$ See, e.g., Beaver et al. (1970) for an empirical analysis that relates accounting information to a firm's beta.
} 
The remainder of this paper is organized as follows. Section 2 sets up the basic model in a world of homogeneous beliefs, defines terms, and derives the determinants of the cost of capital. Sections 3 and 4 analyze the direct and indirect effects of accounting information on firms’ cost of capital, respectively. Section 5 summarizes our findings and concludes the paper.

\section{Model and Cost of Capital Derivation}

We define cost of capital to be the expected return on the firm’s stock. Consistent with standard models of asset pricing, the expected rate of return on a firm j's stock is the rate, $R_{j}$, that equates the stock price at the beginning of the period, $P_{j}$, to the cash flow at the end of the period, $\mathrm{V}_{\mathrm{j}}: \mathrm{P}_{\mathrm{j}}(1+\widetilde{\mathrm{R}} \mathrm{j})=\tilde{\mathrm{V}}_{\mathrm{j}}$, or $\widetilde{R}_{j}=\frac{\tilde{V}_{j}-P_{j}}{P_{j}}$. Our analysis focuses on the expected rate of return, which is $E\left(\tilde{R}_{j} \mid \Phi\right)=\frac{E\left(\tilde{V}_{j} \mid \Phi\right)-P_{j}}{P_{j}}$, where $\Phi$ is the information available to market participants to make their assessments regarding the distribution of future cash flows.

We assume there are $\mathrm{J}$ securities in the economy whose returns are correlated. The best known model of asset pricing in such a setting is the Capital Asset Pricing Model (CAPM) (Sharpe, 1964; Linter, 1965). Therefore, we begin our analysis by presenting the conventional formulation of the CAPM, and then transform this to show how information affects expected returns. In the CAPM, the expected return on a firm’s stock can be expressed as a function of the risk-free rate, $\mathrm{R}_{\mathrm{f}}$, the expected return on the market, $E\left(\widetilde{R}_{m}\right)$, and the firm's beta coefficient, $\beta_{\mathrm{j}}$ :

$$
\mathrm{E}\left(\tilde{\mathrm{R}}_{\mathrm{j}} \mid \Phi\right)=\mathrm{R}_{\mathrm{f}}+\left[\mathrm{E}\left(\tilde{\mathrm{R}}_{\mathrm{M}} \mid \Phi\right)-\mathrm{R}_{\mathrm{f}}\right] \beta_{\mathrm{j}}=\mathrm{R}_{\mathrm{f}}+\frac{\mathrm{E}\left(\tilde{\mathrm{R}}_{\mathrm{M}} \mid \Phi\right)-\mathrm{R}_{\mathrm{f}}}{\operatorname{Var}\left(\tilde{\mathrm{R}}_{\mathrm{M}} \mid \Phi\right)}\left[\operatorname{Cov}\left(\tilde{\mathrm{R}}_{\mathrm{j}}, \tilde{\mathrm{R}}_{\mathrm{m}} \mid \Phi\right)\right]
$$


Eqn. (1) shows that the only firm-specific parameter that affects the firm's cost of capital is its beta coefficient, or, more specifically, the covariance of its future return with that of the market portfolio. This covariance is a forward-looking parameter, and is based on the information available to market participants. Consistent with the conventional formulation of the CAPM, we assume market participants possess homogeneous beliefs regarding the expected end-of-period cash flows and covariances.

Because the CAPM is expressed solely in terms of covariances, this formulation might be interpreted as implying that other factors, for example the expected cash flows, do not affect the firm's cost of capital. It is important to keep in mind, however, that the covariance term in the CAPM is expressed in terms of returns, not in terms of cash flows. The two are related via the equation $\operatorname{Cov}\left(\tilde{R}_{j}, \tilde{R}_{M}\right)=\left[\operatorname{Cov}\left(\frac{\tilde{V}_{j}}{P_{j}}, \frac{\tilde{V}_{M}}{P_{M}}\right)\right]=\frac{1}{P_{j} P_{M}} \operatorname{Cov}\left(\tilde{V}_{j}, \tilde{V}_{M}\right)$. This means that information potentially affects the expected return on a firm's stock through its effect on inferences about the covariances of future cash flows, or through the current period stock price, or both. Clearly the current stock price is a function of the expected-end-of-period cash flow. In particular, the CAPM can be re-expressed in terms of prices instead of returns as follows (see Fama ,1976, eqn. [83]):

$$
P_{j}=\frac{E\left(\tilde{V}_{j} \mid \Phi\right)-\frac{E\left(\tilde{V}_{M} \mid \Phi\right)-\left(1+R_{f}\right) P_{M}}{\operatorname{Var}\left(\tilde{V}_{M} \mid \Phi\right)}\left[\operatorname{Cov}\left(\tilde{V}_{j}, \sum_{k=1}^{J} \tilde{V}_{k} \mid \Phi\right)\right]}{1+R_{f}}, \quad j=1, \ldots, \mathrm{J} .
$$

Eqn. (2) indicates that the current price of a firm can be expressed as the expected end-of-period cash flow minus a reduction for risk. This risk-adjusted expected value is then discounted to the beginning of the period at the risk-free rate. The risk reduction factor in the numerator of eqn. (2) 
has both a macro-economic factor, $\frac{E\left(\tilde{V}_{M} \mid \Phi\right)-\left(1+R_{f}\right) P_{M}}{\operatorname{Var}\left(\tilde{V}_{M} \mid \Phi\right)}$, and a firm-component, which is determined by the covariance of the firm's end-of-period cash flows with those of all other firms. As in Fama (1976), the term $\left[\operatorname{Cov}\left(\tilde{V}_{j}, \sum_{k=1}^{J} \tilde{V}_{k} \mid \Phi\right)\right]$ is a measure of the contribution of firm $j$ to the overall variance of the market cash flows, $\tilde{V}_{M}=\sum_{k=1}^{J} \tilde{V}_{k}$.

Eqns. (1) and (2) express expected returns and pricing on a relative basis: that is, relative to the market. If we make more specific assumptions regarding investors’ preferences, we can express prices and returns on an absolute basis. ${ }^{5}$ In particular, if the economy consists of $\mathrm{N}$ investors with negative exponential utility with risk tolerance parameter $\tau$, the beginning-ofperiod stock price can be expressed as (details in the Appendix):

$$
P_{j}=\frac{E\left(\tilde{V}_{j} \mid \Phi\right)-\frac{1}{N \tau}\left[\operatorname{Cov}\left(\tilde{V}_{j}, \sum_{k=1}^{J} \tilde{V}_{k} \mid \Phi\right)\right]}{1+R_{f}} .
$$

As in eqn. (2), price in eqn. (3) is equal to the expected end-of-period cash flow minus a reduction for the riskiness of firm $\mathrm{j}$, all discounted back to the beginning of the period at the riskfree rate. The discount for risk is now simply the contribution of firm j's cash flows to the aggregate risk of the market divided by the term $\mathrm{N} \tau$, which is the aggregate risk tolerance of the marketplace. The price of the market portfolio can be found by summing eqn. (3) across all firms: $\left(1+R_{f}\right) P_{M}=E\left(\tilde{V}_{M} \mid \Phi\right)-\frac{1}{N \tau} \operatorname{Var}\left(\tilde{V}_{M} \mid \Phi\right)$, which can also be expressed as

\footnotetext{
${ }^{5}$ More specifically, the pricing and return formulas will be expressed relative to the risk free rate, which acts as the numeraire in the economy.
} 
$\frac{1}{N \tau}=\frac{E\left(\tilde{V}_{M} \mid \Phi\right)-\left(1+R_{f}\right) P_{M}}{\operatorname{Var}\left(\tilde{V}_{M} \mid \Phi\right)}$. Therefore, the aggregate risk tolerance of the market determines the risk premium for market-wide risk.

We can re-arrange eqn. (3) to express the expected return on the firm's stock as follows.

Lemma 1. The cost of capital for firm $j$ is

$$
E\left(\tilde{R}_{j} \mid \Phi\right)=\frac{E\left(\tilde{V}_{j} \mid \Phi\right)-P_{j}}{P_{j}}=\frac{R_{f} E\left(\tilde{V}_{j} \mid \Phi\right)+\frac{1}{N \tau}\left[\operatorname{Cov}\left(\tilde{V}_{j}, \sum_{k=1}^{J} \tilde{V}_{k} \mid \Phi\right)\right]}{E\left(\tilde{V}_{j}\right)-\frac{1}{N \tau}\left[\operatorname{Cov}\left(\tilde{V}_{j}, \sum_{k=1}^{J} \tilde{V}_{k} \mid \Phi\right)\right]} .
$$

If we further assume that $\operatorname{Cov}\left(\tilde{\mathrm{V}}_{\mathrm{j}}, \sum_{\mathrm{k}=1}^{\mathrm{J}} \tilde{\mathrm{V}}_{\mathrm{k}} \mid \Phi\right) \neq 0$, this reduces to

$$
E\left(\tilde{R}_{j} \mid \Phi\right)=\frac{R_{f} H(\Phi)+1}{H(\Phi)-1} \text {, where } H(\Phi)=\frac{E\left(\tilde{V}_{j} \mid \Phi\right)}{\frac{1}{N \tau} \operatorname{Cov}\left(\tilde{V}_{j}, \sum_{k=1}^{J} \tilde{V}_{k} \mid \Phi\right)} \cdot
$$

Lemma 1 shows that the cost of capital of the firm depends on four factors: the risk free rate, the aggregate risk tolerance of the market, the expected cash flow of the firm, and the covariance of the firm's cash flow with the sum of all the firms' cash flows in the market. The latter three terms can be combined into the ratio of the firm j's expected cash flows, to firm j's contribution to aggregate risk per-unit-of aggregate risk tolerance. Note that the definition of cost of capital in Lemma 1 does not require that firm j's expected cash flow, or the covariance of that cash flow with the market, be of any particular sign.

In the next result we show how a change in each of the four factors affects cost of capital.

Proposition 1. Ceteris paribus the cost of capital for firm $\mathrm{j}, \mathrm{E}\left(\tilde{R}_{\mathrm{j}}\right)$, is:

(a) increasing (decreasing) in the risk free rate, $\mathrm{R}_{\mathrm{f}}$, when the expected cash flow and the price of the firm have the same (different) sign; 
(b) decreasing (increasing) in the aggregate risk tolerance of the market, $N \tau$, when the expected cash flow and covariance of that cash flow with the market have the same (different) sign;

(c) decreasing (increasing) in the expected end-of-period cash flow, $E\left(\tilde{V}_{j}\right)$, when

$$
\operatorname{Cov}\left(\tilde{\mathrm{V}}_{\mathrm{j}}, \sum_{\mathrm{k}=1}^{\mathrm{J}} \tilde{\mathrm{V}}_{\mathrm{k}}\right) \text { is positive (negative); and }
$$

(d) increasing (decreasing) in $\operatorname{Cov}\left(\tilde{\mathrm{V}}_{\mathrm{j}}, \sum_{\mathrm{k}=1}^{\mathrm{J}} \tilde{\mathrm{V}}_{\mathrm{k}}\right)$ when $\mathrm{E}\left(\tilde{\mathrm{V}}_{\mathrm{j}}\right)$ is positive (negative).

To make the intuition that underlies Proposition 1 as transparent as possible, consider the case in which firm j's expected end-of-period cash flow, the covariance between its end-of-period cash flows and the market, and the firm's beginning-of-period stock price are all positive. Here, the reason why the expected return on firm $\mathrm{j}$ is increasing in the risk-free rate is clear, because this provides the baseline return for all securities. When $\mathrm{N} \tau$ increases, the aggregate risk tolerance of the market increases; hence, the discount applied to each firm's riskiness decreases. ${ }^{6}$ This moves the firm's expected rate of return closer to the risk-free rate. When $\operatorname{Cov}\left(\tilde{\mathrm{V}}_{\mathrm{j}}, \sum_{\mathrm{k}=1}^{\mathrm{J}} \tilde{\mathrm{V}}_{\mathrm{k}}\right)$ increases, the contribution of the riskiness of firm j's cash flows to the overall riskiness of the market goes up; hence, the expected return must increase to compensate investors for the increase in risk. This is one of the key insights of the CAPM (Sharpe, 1964; Lintner, 1965).

The most surprising result is that an increase in the expected value of cash flows decreases the expected rate of return. The intuition, however, is fairly straightforward. Consider a firm with two components of cash flow: a riskless component $\left(\mathrm{V}_{\mathrm{j}}^{\mathrm{a}}\right)$ and a risky component $\left(V_{j}^{b}\right)$. Clearly the cost of capital for the firm will be somewhere in between the cost of capital

\footnotetext{
${ }^{6}$ This is analogous to the effect discussed in Merton (1987).
} 
for the riskless component and the cost of capital for the risky component. But if the firm's expected cash flow increases without affecting the firm's variances or covariances, this is exactly analogous to adding a new riskless component of cash flows to the firm's existing cash flows. The firm's cost of capital therefore decreases.

The results above vary one effect at a time, holding the others constant. But what if the expected cash flows and the covariance change simultaneously? For the special case where expected cash flows and the covariance both change in exactly the same proportion, it is easy to see that the numerator and denominator each change by that proportion in eqn. (4), and thus cancel out. In this special case, there is no effect on the cost of capital. There is an effect, however, for any simultaneous change that is not exactly proportionate on the two terms.

While it is common in some corporate finance and valuation models to assume that the level of cash flow and the covariances move in exact proportion to each other (i.e., all cash flows are from the same risk class), we are unaware of any theoretical results or empirical evidence to suggest this should be the case. On the contrary, the existence of fixed costs in the production function, economies of scale, etc., generally make the expected values and covariances of firm's cash flows change in ways that are not exactly proportional to each other. Moreover, there is ample empirical evidence that betas vary over time, which implies the ratio of expected cash flow to overall covariance varies, suggesting that new information has an impact as it becomes available.

There is nothing in Proposition 1 that is specific to accounting information. Any shock new regulations, taxes, inventions, etc. - that affects the $\mathrm{H}$ term has a corresponding effect on the firm's expected return. In the following two sections we focus on how accounting information impacts the $\mathrm{H}(\Phi)$ ratio in the cost of capital equation. In section 3, we show how, holding the 
real decision of the firm fixed, accounting information affects the assessments made by market participants of the distribution of future cash flows, and how this assessment impacts the firm's cost of capital. In section 4, we show that accounting information affects real actions within the firm, and that this naturally leads to changes in the risk-return characteristics of the firm, thereby affecting the firm's cost of capital.

\section{Direct Effects of Information on the Cost of Capital}

In this section we hold constant the real (operating, investing, and financing) decisions of the firm (we relax this in Section 4). Even though accounting and disclosure policies do not affect the real cash flows of the firm here, they affect the assessments that market participants have regarding the distribution of these future cash flows. As a result, they affect equilibrium stock prices and expected returns. In particular, eqns. (3) and (4) show that stock price and the expected return are, respectively, decreasing and increasing functions of the covariance of a firm's end-of-period cash flow with the sum of all firms' end-of period cash flows. In the next two sub-sections, we discuss the two components of this covariance: the firm's own variance and the covariances with other firms, $\operatorname{Cov}\left(\tilde{V}_{j}, \sum_{k=1}^{J} \tilde{V}_{k}\right)=\operatorname{Cov}\left(\tilde{V}_{j}, \tilde{V}_{j}\right)+\operatorname{Cov}\left(\tilde{V}_{j}, \sum_{k \neq j} \tilde{V}_{k}\right)$.

\subsection{Direct Effects - Through the Variance of the Firm's Cash Flow}

The idea that better quality accounting information reduces the assessed variance of the firm's cash flow is well known. As an application, consider the impact on the cost of capital of firm $\mathrm{j}$ if more information becomes available (either through more transparent accounting rules, additional firm disclosure, or greater information search by investors). Suppose the firm's investment decisions have been made; let $\mathrm{V}_{0 \mathrm{j}}$ and $\omega_{\mathrm{j}}$ represent the ex-ante expected value and 
ex-ante precision of the end-of-period cash flow, respectively. Suppose investors receive Q independently distributed signals, $\mathrm{z}_{\mathrm{j} 1}, \ldots, \mathrm{z}_{\mathrm{jQ}}$, about the ultimate realization of firm $\mathrm{j}$ 's cash flow, where each signal has precision $\gamma_{\mathrm{j}}$. Then investors' posterior distribution for end-of-period cash flow has a normal distribution with mean

$$
E\left(\tilde{V}_{j} \mid z_{j 1}, \ldots, z_{j Q}\right)=\frac{\omega_{j}}{\omega_{j}+Q \gamma_{j}} V_{0 j}+\frac{\gamma_{j}}{\omega_{j}+Q \gamma_{j}} \sum_{q=1}^{Q} z_{j q} \text {, and precision } \omega_{j}+Q \gamma_{j}
$$

Therefore, using part $\mathrm{d}$ of Proposition 1, the expected return is a decreasing function of the precision, $\omega_{j}+Q \gamma_{j}$. This implies that the firm's cost of capital declines with: 1) an increase in the prior precision, $\left.\omega_{j} ; 2\right)$ the number of new signals, Q; or 3) the precision of these signals, $\gamma_{j}$. The firm-specific variance reduction effect is an important factor in the cost of capital analysis of Easley and O'Hara (2004). While their paper models a multi-security economy, the assumption that all cash flows are independently distributed implies that the pricing of each firm is also done independently. In particular, if we simplify their model to remove the private information component of their model, their pricing equation reduces to:

$$
P_{j}=E\left(\tilde{V}_{j}\right)-\frac{\bar{x}}{N \tau} \frac{1}{\omega_{j}+Q \gamma_{j}},
$$

where $\bar{x}$ is the supply of the risky asset (and the analysis assumes the risk-free rate is zero). Therefore, the impact of information on the equilibrium price is similar to our eqn. (3). ${ }^{7}$ As more public signals are generated, the assessed variance of the firm's cash flows goes down.

\footnotetext{
${ }^{7}$ In other work, we show that, contrary to their claims, the other effect on the cost of capital in Easley and O'Hara (2004) is not driven by the asymmetry of information across investors. Instead, it is the average precision of investor's information that is the determinant of the cost of capital in their model. Moreover, the same argument we use here implies that their "information effect," regardless of their interpretation, is diversifiable as the economy gets large.
} 
The analysis above formalizes the notion that accounting information and disclosure reduce the assessed variance of the firm's end-of-period cash flows. As eqn. (3) shows, this is one of the components of the covariance of the firm's cash flow with those of all firms. Therefore, ceteris paribus, reducing the assessed variance of the firm's cash flows increases the firm's stock price and reduces the firm's expected return. Moreover, because this is an additively separate term in the overall covariance, the magnitude of this impact on price does not depend on how highly the firm's cash flows co-vary with those of other firms. For example, a decrease of, say, 10 percent in the assessed variance of firm cash flows has the same dollar effect on stock price regardless of the degree of covariance with other cash flows. Clearly, for a given finite value of $\mathrm{N}$ (the number of investors) and $\mathrm{J}$ (the number of firms in the economy), there is a non-zero effect on price and on the cost of capital of reducing the assessment of firm-variance.

Next we address the question of the diversifiability (or magnitude) of the effect of reducing the market's assessed variance of the firm's cash flows. Intuitively, the notion that a risk is diversifiable is usually expressed in terms of how it affects the variance of a portfolio as the number of firms in the portfolio gets large. ${ }^{8}$ To examine this more rigorously, we must ensure that economy-wide risks are absorbed by the market participants collectively, and economy-wide risks are priced. This implies that $\mathrm{J}$ (the number of securities) and $\mathrm{N}$ (the number of investors) must both get large. To see this, consider as one polar case a situation in which the number of firms in the economy increases, while holding the number of investors fixed. This does make the contribution of firm variance small relative to the covariance with all firms (assuming firms' covariances tend to be positive). It also increases, however, the aggregate risk

\footnotetext{
${ }^{8}$ In particular, the variance of an equally weighted portfolio of $\mathrm{J}$ securities can be expressed as $\operatorname{Variance}\left(\frac{1}{J} \sum_{j} \widetilde{R}_{j}\right)=\frac{1}{J} \operatorname{AverageVar}\left(\tilde{R}_{j}\right)+\frac{J-1}{J} \operatorname{AverageCov}\left(\tilde{R}_{j}, \tilde{R}_{k}\right)$. As $J$ gets large this converges to the average covariance between the returns in the portfolio. The individual variances of the firms' returns asymptotically disappear.
} 
in the economy: that is, $\sum_{k=1}^{J} \operatorname{Cov}\left(\tilde{V}_{j}, \tilde{V}_{k}\right)$ increases without bound. This drives prices lower and results in an infinite increase in the expected return required to hold the stock (see eqns. [3] and [4]). On the other hand, consider as the other polar case a situation where $\mathrm{N}$, the number of investors in the economy, spreads all risks (not just firms’ variances) over more investors, which reduces all risk premiums and decreases all expected returns. In the limit, $\frac{1}{N} \sum_{k=1}^{J} \operatorname{Cov}\left(\tilde{V}_{j}, \tilde{V}_{k}\right)$ approaches zero for each firm and even for the market; therefore, no risks are priced. To avoid these uninteresting, polar cases, $\mathrm{J}$ and $\mathrm{N}$ must both increase for the notion of “diversifiability” to be meaningful.

When $\mathrm{J}$ and $\mathrm{N}$ both increase, the effect of firm-variance on the cost of capital, $\frac{1}{N \tau} \operatorname{Cov}\left(\tilde{V}_{j}, \tilde{V}_{j}\right)$, asymptotically approaches zero, because this term only appears once in the overall covariance for a firm. ${ }^{9}$ The covariance with other firms, however, $\frac{1}{N \tau} \sum_{k \neq j} \operatorname{Cov}\left(\tilde{V}_{j}, \tilde{V}_{k}\right)$, survives because the number of covariance terms ( $\mathrm{J}-1)$ also increases as the economy gets large. In the next section, we analyze how information affects the covariance terms.

\subsection{Direct Effect - Through the Covariance with other Firms’ Cash Flows}

In this section, we show that information about a firm's future cash flows also affects the assessed covariance with other firms. Our work in this section builds on the estimation risk literature in finance (See Brown,1979; Barry and Brown;1984 and 1985; Coles and

\footnotetext{
${ }^{9}$ In our simplified version of the Easley and O’Hara result (our eqn. [5]), as N gets large, the last term on the righthand side of the equation approaches zero. Therefore, the firm is priced as if it is riskless (recall that Easley and O’Hara assume there are no covariances with other firms). Similarly, in their "full blown" model (see their proposition 2), as $\mathrm{N}$ gets large the per-capita supply of the firm's stock goes to zero, and again the pricing equation collapses to a risk-neutral one.
} 
Loewenstein,1988; and Coles et al., 1995). Specifically, our work differs from this literature in three important ways. First, the estimation risk literature generally focuses on the impact of the information environment on the beta of the firm, whereas our focus is on the cost of capital. Because the information structures analyzed in this literature generally affect all firms in the economy, the impact on beta is confounded by the simultaneous impact on the covariances between firms and the variance of the market portfolio. This is one reason why they obtain results that are mixed or difficult to sign. By focusing on the cost of capital, we can analyze the impact of both effects.

Second, the estimation literature focuses on very specific changes in the information environment. Some papers examine the impact of increasing equally the amount of information for all firms. Other papers compare two information environments: an environment where all firms have an equal amount of information to an environment where one subgroup of firms has more information available than does a second group. Our framework allows us to analyze more general changes in information structures: both mandatory and voluntary. In particular, unlike the prior literature, we are able to address the question of how more information about one firm affects its own cost of capital within an unequal information environment.

Finally, our model represents the information signals differently than in the estimation risk literature. The estimation risk literature assumes the information signals available about the firms arise from historical time-series observations of the firms returns. While this literature claims that the intuition behind their results applies to information more generally, the assumed time-series nature of their information signals drives a substantial element of the covariance 
structure in their models. In particular, new information signals are conditionally correlated with contemporaneously observed signals and conditionally independent of all other signals. ${ }^{10}$

We model a more general information structure that allows us to examine alternative covariance structures of the signals. Specifically, we model information signals as representing noisy measures of the variables of interest, which are end-of-period cash flows. That is, an information signal, $\tilde{Z}_{\mathrm{j}}$, about firm j's cash flow, $\tilde{V}_{\mathrm{j}}$, is modeled as $\tilde{Z}_{j}=\tilde{V}_{j}+\widetilde{\varepsilon}_{j}$, where $\widetilde{\varepsilon}_{j}$ is the "noise” or "measurement error" in the information signal. Depending on the correlation structure assumed about the cash flows and error terms, $\tilde{Z}_{j}$, could also be informative about the cash flow of other firms, as well as informative in updating the assessed variances and covariances of end-of-period cash flows. This formulation of information is consistent with the way information is modeled in virtually all conventional statistical inference problems (see DeGroot, 1970). It is also consistent with virtually all papers in the vast noisy rational expectations literature in accounting and finance (see Verrecchia, 2001, for a review).

Our characterization of disclosures as noisy signals about firms’ future cash flows (or other performance measures) also corresponds to actual disclosure practices. Firms disclose information about their earnings, which is the sum of their market, industry, and idiosyncratic components. Similarly, other disclosures such as revenues or cash flow are also about the firm

\footnotetext{
${ }^{10}$ See Kalymon (1971) for the original derivation of the covariance matrix used in much of this literature.
} 
as whole. ${ }^{11}$ Analysts' forecasts of future earnings are about the earnings of the firm, not just of the "firm specific" component of future earnings. ${ }^{12}$

To provide a simple initial example, suppose that the future cash flows for two firms have an ex-ante covariance of $\operatorname{Cov}\left(\tilde{V}_{j}, \tilde{V}_{k}\right)$, which is non-zero. Suppose we observe an information signal about firm $\mathrm{j}, \tilde{Z}_{j}$, which is a noisy signal about firm j's future cash flow, $\tilde{V}_{j}$. For convenience, assume that the error term $\widetilde{\varepsilon}_{j}$ is uncorrelated with either of the true cash flows $\tilde{V}_{j}$ or $\tilde{V}_{k}$. As in the previous section, a greater precision of the information signal $\tilde{Z}_{j}$ about firm j’s cash flow leads to a smaller posterior variance of $\tilde{V}_{j}$.

Moreover, we can also show that the information signal $\tilde{Z}_{j}$ also leads to an updating of the covariance between the two cash flows $\tilde{V}_{j}$ and $\tilde{V}_{k}$. In particular, it is straightforward to show the following.

Proposition 2. The covariance between the cash flows of firms $\mathrm{j}$ and k conditional upon a signal about firm j's cash flow moves away from the unconditional $\operatorname{Cov}\left(\tilde{V}_{j}, \tilde{V}_{k}\right)$ and closer to zero as the precision of firm j’s signal increases. Specifically,

$$
\operatorname{Cov}\left(\tilde{V}_{j}, \tilde{V}_{k} \mid Z_{j}\right)=\operatorname{Cov}\left(\tilde{V}_{j}, \tilde{V}_{k}\right) \frac{\operatorname{Var}\left(\tilde{\varepsilon}_{j}\right)}{\operatorname{Var}\left(\tilde{Z}_{j}\right)}
$$

\footnotetext{
${ }^{11}$ In contrast, Hughes et al. (2005) model information signals as being artificially decomposed into "market" and "idiosyncratic factors." Moreover, in our model cash flows have a completely general variance-covariance structure, whereas the analysis in Hughes et al. assumes a very specific "factor" structure. Similarly, the betas and covariances that turn out to be relevant in our pricing equations are relative to the market portfolio (the sum of all firm's cash flows), whereas in Hughes et al. the betas and covariances are relative to the exogenously specified "common factors."

${ }^{12}$ While the idea that the earnings of a firm can be useful in predicting future cash flows of the industry or the market as a whole might seem counterintuitive, there is empirical evidence to support this. See Piotroski and Roulstone (2004) about how the activities of market participants (analysts, institutional traders, and insiders) impacts the incorporation of firm specific versus industry versus market components of future earnings into prices. See also the "information transfer" literature (e.g., Foster, 1981). As we show, it is not necessary that there be a "large" effect of firm j’s disclosures on other firms.
} 
Therefore, the conditional covariance between $\tilde{V}_{j}$ and $\tilde{V}_{k}$ is equal to the unconditional covariance, times a factor that can be interpreted as the percentage of the variance of the information signal that consists of noise or measurement error.

As the measurement error in $\tilde{Z}_{j}$ goes down, the assessed covariance between $\tilde{V}_{j}$ and $\tilde{V}_{k}$ decreases (in absolute value). The intuition is as follow. If there is infinite measurement error in $\tilde{Z}_{j}$, then observing $\tilde{Z}_{j}$ does not communicate anything. Therefore, there is no need to update an assessment of the unconditional variance of $\tilde{V}_{j}$, or the unconditional covariance between $\tilde{V}_{j}$ and $\tilde{V}_{k}$. At the other extreme, if there is no measurement error in $\tilde{Z}_{j}$, then observing $\tilde{Z}_{j}$ is the same as observing $\tilde{V}_{j}$. But if $\tilde{V}_{j}$ is observed, there is no further covariance between $\tilde{V}_{j}$ and $\tilde{V}_{k}$; hence, the assessed covariance goes to zero. Note that Proposition 2 does not require that the unconditional covariance between $\tilde{V}_{j}$ and $\tilde{V}_{k}$ be positive; as the measurement error in $\tilde{Z}_{j}$ goes down, the assessed covariance between $\tilde{V}_{j}$ and $\tilde{V}_{k}$ moves closer to zero, irrespective of its sign. Proposition 2 applies equally to the conditional covariances with all other firms in the economy. This implies that

$$
\sum_{k=1}^{J} \operatorname{Cov}\left(\tilde{V}_{j}, \tilde{V}_{k} \mid Z_{j}\right)=\sum_{k=1}^{J} \frac{\operatorname{Var}\left(\tilde{\varepsilon}_{j}\right)}{\operatorname{Var}\left(\tilde{Z}_{j}\right)} \operatorname{Cov}\left(\tilde{V}_{j}, \tilde{V}_{k}\right)=\frac{\operatorname{Var}\left(\tilde{\varepsilon}_{j}\right)}{\operatorname{Var}\left(\tilde{Z}_{j}\right)} \operatorname{Cov}\left(\tilde{V}_{j}, \sum_{k=1}^{J} \tilde{V}_{k}\right)
$$

Therefore, the conditional covariance between the cash flows of firm $\mathrm{j}$ and those of the market as a whole is proportional to the amount of measurement error in the information signal about firm j's cash flow. Moreover, this effect does not diversify away in large economies: the effect is present for each and every covariance term with firm $\mathrm{j}$. 
For example, suppose the distribution of cash flows is represented as a "single-factor index model," so that the cash flow for firm $\mathrm{j}$ is $\tilde{V}_{j}=a_{j}+b_{j} \tilde{\theta}+\tilde{u}_{j}$, where $\theta$ is a "market factor" and $\mathrm{u}_{\mathrm{j}}$ is a firm specific factor. For convenience, let all the $\mathrm{u}_{\mathrm{j}}$ 's be distributed independently. Let the information signal about firm $\mathrm{j}$ be a noisy measure of its cash flow, $\tilde{Z}_{j}=\tilde{V}_{j}+\tilde{\varepsilon}_{j}$, where the error terms are distributed independently of the true cash flows, as well as each other. Then the unconditional covariance between the cash flows of firms $\mathrm{j}$ and $\mathrm{k}$ is $\mathrm{b}_{\mathrm{j}} \mathrm{b}_{\mathrm{k}} \operatorname{Variance}(\tilde{\theta})$, and the conditional covariance given the signal $\mathrm{Z}_{\mathrm{j}}$ is $\operatorname{Cov}\left(\tilde{V}_{j}, \tilde{V}_{k} \mid Z_{j}\right)=b_{j} b_{k} \operatorname{Variance}(\tilde{\theta}) \frac{\operatorname{Variance}\left(\tilde{\varepsilon}_{j}\right)}{\operatorname{Variance}\left(\tilde{Z}_{j}\right)}$, which implies $\operatorname{Cov}\left(\tilde{V}_{j}, \sum_{k \neq j} \tilde{V}_{k} \mid Z_{j}\right)=b_{j} \operatorname{Variance}(\tilde{\theta}) \frac{\operatorname{Variance}\left(\tilde{\varepsilon}_{j}\right)}{\operatorname{Variance}\left(\tilde{Z}_{j}\right)} \sum_{k \neq j} b_{k}$ As before, the posterior covariance between firm $\mathrm{j}$ and "the market" decreases as the quality of the information about firm j's future cash flow improves.

These findings are in contrast to those in a concurrent paper by Hughes et al. (2005), which employs more restrictive and less natural information structures. For example, Hughes et al. show that if the information concerns exclusively the idiosyncratic component of a firm's cash flows, not the cash flows per se, and the information signal matrix is exclusively diagonal, then there is no covariance effect. That is, under these conditions, the information signals are, by definition, unrelated to the component of cash flows that varies across firms, so they cannot be useful in updating the assessed covariance.

Hughes et al. also considers an information structure that relates only to the "common factor" portion of cash flows. In this case, information does affect the covariance between a firm's cash flows and the common factors. Similarly, the covariance between the cash flows of 
any two firms that are both affected by this common factor will also change. While this result is similar in some ways to ours, the nature of the cross-sectional impact on the covariance, and therefore the cost of capital, differs in their paper because of the different information structure assumed.

When the information is about the cash flow as a whole, we find that virtually any more general representation of $\tilde{V}_{j}, \tilde{V}_{k}, \tilde{Z}_{j}$ and/or $\tilde{Z}_{k}$ results in $\tilde{Z}_{j}$ and $\tilde{Z}_{k}$ changing the covariance of $\tilde{V}_{j}$ and $\tilde{V}_{k}$, which is the effect that we obtain in our general variance-covariance framework. Thus, we claim that in general information about firm cash flows (or other measures of firm performance) has a covariance effect, and hence leads to cross-sectional differences in firms' cost of capital. In particular, at the extreme, if information could fully reveal the firm's future cash flow, the cash flow would, by definition, be riskless and the cost of capital on the firm's stock would converge to the risk free rate.

It is possible to expand the analysis in this section in several ways. For example, in Proposition 2, we refer to the covariance between the cash flows of firms $\mathrm{j}$ and $\mathrm{k}$ conditional on (a single) firm j providing information about its cash flow. In the proof of Proposition 2 in the appendix, we offer a more general result based on computing the covariance of cash flows conditional on both firms $\mathrm{j}$ and $\mathrm{k}$ providing information about their respective cash flows. The analysis could be generalized further to allow all firms in the economy to provide information about their respective cash flows. It is important to point out that, even in the case where all firms provide information, it is not necessarily the case that the uncertainty about the market cash 
flow is eliminated. If each firm discloses its realized cash flow with noise, uncertainty about the market cash flow will grow as the number of firms in the economy grows. ${ }^{13}$

Another possible extension is that in our paper (as is true in most of the rational expectations literature) we interpret the signals as being related to the realized cash flow. We can also conduct the analysis by interpreting them instead as signals about the future expected cash flow (or parameters of the distribution of future cash flows). In fact, most of the estimation risk literature interprets the signals in this way. Of course, when learning about the expected future cash flow, as opposed to the realized future cash flow, a perfect signal does not resolve all uncertainty, so the asset does not become riskless. Nonetheless, better information reduces the covariances. We can also repeat the analysis under alternative assumptions regarding what parameters of the distribution of future cash flows are uncertain: 1) the expected cash flows are unknown but the covariance matrix is known; or 2) the expected cash flows and the covariance matrix are both unknown. We could also allow the error terms ( $\tilde{\varepsilon}_{j}$ 's) to be correlated across firms and examine the implications of this.

\subsection{The Effects of Mandatory Disclosures}

In the previous sections, we analyze the impact of changing the quality of accounting information for a single firm on its price and cost of capital. We now briefly discuss the effects of mandatory disclosure of accounting information. The main difference is that disclosure regulation affects all firms. Therefore, in addition to the impact of firm j's disclosure on, say, the covariance between the cash flows of firms $j$ and $k$, there is an additional impact on this covariance by firm k’s disclosures. In principle, disclosure by other firms can have a (small)

\footnotetext{
${ }^{13}$ In contrast, if each firm discloses the aggregate market cash flow with idiosyncratic noise, disclosures by many firms reveals the market cash flow in the limit; thus, there would be no aggregate uncertainty. This information structure, however, is not very descriptive of what firms do.
} 
impact on the covariance with firm j. That is, each firm's disclosure has an externality on other firms' cost of capital. This positive externality provides potentially a reason why there could be benefits to disclosure regulation, rather than relying on voluntary disclosures, because firms will not take this externality into account when deciding the optimal level of voluntary disclosure. While this effect is small individually, it could become large collectively. ${ }^{14}$

Using our framework, it is therefore straightforward to show that increasing the quality of mandated disclosures reduces the cost of capital for all firms in the economy (assuming that the expected cash flow of each firm in the economy and the covariance of that firm's cash flow with the market have the same sign). The magnitude of the impact of mandatory disclosure, however, on a particular firm's cost of capital is less clear-cut. Even if mandatory disclosures affect all elements of the covariance matrix of future cash flows by a scale factor, the effect on the cost of capital is not proportionate for all firms. It follows from the pricing formula in eqn. (2) that even if the impact on the covariances of future cash flows is proportionate, the effect on the expected values of future cash flows is unlikely to have the same scale factor. Therefore, the prices of all firms will not change proportionately. Thus, using eqn. (4), the firms' expected returns (and cost of capital) will not change by the same proportion for all firms either. ${ }^{15}$

Moreover, it seems unlikely that mandated disclosures alters the entire covariance matrix of all firms' future cash flows by the same scale factor. The amount of new information provided by a particular mandated disclosure depends on what other information the firm already

\footnotetext{
${ }^{14}$ See Admati and Pfleiderer (2000) and Fishman and Hagerty (1989) for other externality-based explanations of mandatory disclosure.

${ }^{15}$ Some early models in the estimation risk literature in finance (e.g., Kalymon, 1971; Brown, 1979) assumed that information had a proportionate impact on the covariance matrix of returns, and some found that information would not affect the betas of firms. This result occurred because (by assumption) all the covariances and variances of firms' returns changed proportionately. Therefore, there was no effect on the beta coefficient of returns, which is the ratio of the covariance of the firm's return to the market divided by the variance of the market return, because the numerator and denominator changed by the same scale factor. It is more natural to assume, however, that the impact of information is on the assessed distribution of cash flows, not returns. See Coles and Lowenstein (1988) for similar discussion.
} 
discloses. For some firms, this disclosure requirement duplicates other disclosures, in which case it provides no additional information; for others it may provide a small amount of incremental information, and for others still it may be completely new. These information effects imply an unequal impact of disclosure regulation on the individual elements of the covariance matrix of future cash flows. Thus, firms are likely to benefit from mandatory disclosures differentially.

It is important to distinguish between the impact of mandated disclosure on the cost of capital and the impact on the beta coefficient. Our formulation allows us to express the cost of capital in a reduced form that depends on assessed covariance between the cash flow of the firm and the cash flows of all firms in the market. Even though mandated disclosure reduces the cost of capital for firms, this does not imply that it reduces all beta coefficients similarly. Instead, the lowered covariance between end-of-period cash flows implies a reduction in the product of the impact on the market risk premium and the beta coefficient; it does not imply a reduction in the beta coefficient separately. In fact, the average beta in the economy must still be 1.0, regardless of the quality of the information environment. Therefore, mandated disclosure cannot reduce all firms’ betas. This suggests that researchers interested in examining the effect of mandated disclosures on costs of capital must look to alternative measures for cost of capital than the beta coefficient.

\section{Indirect Effects of Information on Cost of Capital}

In this section, we show how the quality of the accounting and disclosure system has an indirect impact the firm's cost of capital through its effect on real decisions that impact the expected cash flows and covariances of cash flows. Clearly, decision-makers in an economy

make decisions on the basis of the information they have available to them. If this information 
changes, so will their decisions. To the extent these new decisions alter the distribution of the firm's end-of-period-cash flow, this impacts the firm’s cost of capital. In particular, as we showed in Proposition 1, if the ratio of the firm's expected cash flow to the covariance between the firm's cash flow and the sum of all other firms' cash flows changes (our parameter H in our Lemma 1), the expected rate of return on the firm's stock will change, and by definition, so will its cost of capital.

The potential scope of the decisions that a firm’s accounting and disclosure systems may affect can be quite broad. In addition to the decisions of investors and creditors, a firm’s accounting and disclosure systems may affect managerial actions, as well as the potential actions of competitors, regulatory authorities, etc. The impact on the firm's cost of capital can be either positive or negative. To be able to predict the "indirect effect" of accounting information on the firm's cost of capital therefore requires the researcher to carefully specify: 1) the link between information and these decisions; and 2) the impact of these decisions on the distribution of future cash flows. We provide two simple examples to illustrate these issues. In one, accounting information affects the amount of cash that is appropriated from investors. In the second, accounting information changes a manager’s investment decisions.

\subsection{Information, Governance, and Appropriation}

Many papers (e.g., in agency theory) have suggested that better financial reporting and/or corporate governance increases firm value by reducing the amount that managers appropriate for themselves (e.g., LaPorta et. al., 1997; Lambert, 2001). These papers, however, do not discuss the impact that these systems have on the firm's cost of capital. In fact, some of them claim that these systems have a "one-time” effect on price, but do not affect the cost of capital as defined 
by the discount rate implicit in the firm's stock valuation. An exception is Lombardo and Pagano (2000) (LP), a paper that also analyzes the impact of governance and appropriation on firm's cost of capital. We compare our model and results to LP below.

Represent the "gross" end-of-period cash flow of firm j before any appropriation by $\tilde{V}_{j}^{*}$. As before, we assume this cash flow has a normal distribution. Managers appropriate for themselves an amount A that decreases with the quality of the information and/or governance systems. By accounting systems here, we do not mean simply the disclosures the firm makes to outsiders, but also internal control systems, corporate governance policies, etc. ${ }^{16}$ Clearly, a more sophisticated analysis could be conducted that endogenously derives the functional form of A and/or determines the types of information that lead to the largest reductions in A, but these features are not necessary to make our point.

In particular, the amount of the firm's end-of-period cash flows that is appropriated from shareholders is $A(Q)=A_{0}(Q)+A_{1}(Q) V_{j}^{*}$, where $Q$ is the quality of the accounting system, etc., and $\mathrm{V}^{*}$ is the value of the firm gross of any appropriation. ${ }^{17}$ A higher quality accounting system is assumed to reduce the amount of misappropriation: $\mathrm{A}_{0}^{\prime} \leq 0$ and $\mathrm{A}_{1}^{\prime} \leq 0$. This means that the net amount received by the firm's shareholders is

$$
\tilde{V}_{j}=\tilde{V}_{j}^{*}-A(Q)=\left(1-A_{1}(Q)\right) \tilde{V}_{j}^{*}-A_{0}(Q)
$$

\footnotetext{
${ }^{16}$ More generally, the amount a manager could appropriate would also depend on dimensions of the legal system, such as the ability to bring lawsuits against the firm and/or managers.

${ }^{17} \mathrm{LP}$ analyze a model that also has a parameter analogous to our $\mathrm{A}_{1}$, which reduces the cash flow available to shareholders by a fractional amount. LP do not have a parameter, however, that corresponds exactly to our $\mathrm{A}_{0}$, which reduces the end-of-period cash flow by a constant. Instead LP have a cost that shareholders pay out of their own pocket for auditing and legal fees. This fee is proportional to the share price, which obviously depends on the expected end-of-period cash flow. Another difference is that in LP appropriation parameters are economy-wide (or for segments of the market), whereas ours can be firm-specific. Finally, we explicitly analyze the impact the appropriation parameters have on the riskiness of the end-of-period cash flow (variances and covariances), whereas these are not issues addressed in LP.
} 
This representation allows us to calculate the expected value of the firm's cash flow and its covariance with other firms' cash flows as a function of the quality of the information and/or governance quality parameter, Q. We can then apply Lemma 1 to determine the effect on the firm's cost of capital.

Proposition 3: Higher quality information that reduces managerial misappropriation of the firm's cash flow weakly reduces the firm's cost of capital. If $\mathrm{A}_{0}=0$ and $\mathrm{A}_{0}^{\prime}=0$ (so that information only affects the $\mathrm{A}_{1}$ term), then information has no effect on the cost of capital. Otherwise, improved information lowers the cost of capital to the firm.

One special case arises when the quality of the information and/or governance system affects only the "fixed amount" $\left(\mathrm{A}_{0}\right)$ the manager appropriates. In this case, increasing the quality of the accounting system increases the expected cash flow available to shareholders by reducing $\mathrm{A}_{0}$. It does not affect, however, the covariance of the firm's net cash flows with those of other firms. Therefore, not surprisingly, a higher quality accounting system increases the price of the firm. What is more surprising is that the information system also leads to a change in the firm's cost of capital. Our model shows that the reason is straightforward: the ratio of the expected cash flows to the covariance shifts.

At the other extreme, suppose the quality of information affects only the "proportion" of the firm's cash flow the manager appropriates: the parameter $A_{1}$. In this case, improving the quality of the firm's information and/or governance system increases the proportion of the firm's cash flow available to shareholders. This not only increases the firm's expected cash flow, but it also increases the covariance of the firm's cash flows with other firms by the same proportion. ${ }^{18}$

\footnotetext{
${ }^{18}$ Technically, the total covariance does not change in exact proportion to the expected value because the firm's covariance with itself will change with the square of the proportionality factor. As in the previous section, however, the impact of the firm's own variance on the cost of capital goes to zero as the number of investors gets large. In
} 
Therefore, the ratio of expected cash flow to covariance of cash flows does not change, and the firm's cost of capital is unaffected. LP establishes a similar result. Price increases, but there is no impact on the firm's expected rate of return given this "one time” effect on price.

In fact, Proposition 3 indicates that the assumption that the manager's appropriation is exactly a fixed proportion of the end-of-period cash flow is the only situation in which there is no impact on the cost of capital. As long as there is a component of appropriation that does not vary with the realization of the end-of-period-cash flow (for example, if it depends on the expected end of period cash flow instead of the realization), or the quality of information affects the "fixed" component of appropriation, there will be a non-zero impact on the cost of capital.

We can also interpret the parameters $\mathrm{A}_{0}$ and $\mathrm{A}_{1}$ as cash flow appropriated by other firms, as opposed to by the manager. This allows us to tie our results to the large literature in accounting on the proprietary costs of disclosure (see Verrecchia, 2001). In this literature, increased disclosure allows other firms to make better strategic decisions to compete away some of the profits of the disclosing firm We can adapt our model to this situation by assuming that increased disclosure quality will increase $\mathrm{A}_{0}$ or $\mathrm{A}_{1}$. The comparative statics are straightforward, and in this case increased disclosure quality weakly increases the firm's cost of capital. In particular, the most common assumption in the literature for the functional form of the proprietary costs is that they reduce profits by a constant. In this case, improved accounting information and disclosure increases $A_{0}$, and strictly increases the firm's cost of capital.

Finally, suppose improved accounting and disclosure influences the governance of all firms, as in a mandatory change such as the Sarbanes-Oxley Act of 2002. Again, the impact of the indirect effects on the cost of capital is ambiguous. As above, if improved disclosure shifts 
only the "fixed" component of managerial misappropriation, firms' cost of capital decreases. The results are different, however, for the case where improved disclosure impacts only the proportion $\left(\mathrm{A}_{1}\right)$ of the cash flow appropriated by the manager. ${ }^{19}$ As above, the firm's expected cash flow rises by a factor of (1- $\left.\mathrm{A}_{1}\right)$. Because the cash flows of all firms shift proportionately, the covariances of cash flows increase by a factor of $\left(1-\mathrm{A}_{1}\right)^{2}$. In this case, mandatory disclosure increases the firm's cost of capital.

While this might seem unintuitive, the reason is straightforward. When the quality of information and/or governance is poor, managers appropriate a considerable amount of the payoff; in addition, they also absorb a considerable amount of risk. Managers do not mind bearing this risk because they did not have to pay anything to acquire the appropriated payoff. When accounting quality increases, however, managers steal less, so more of the payoff goes to shareholders. But this implies that there is more risk in the economy, and this extra risk is perfectly correlated with the existing risk. Therefore, the risk increases faster than the expected payoff from the market (by a factor of $\left[1-\mathrm{A}_{1}\right]^{2}$ versus $1-\mathrm{A}_{1}$ ), so the aggregate risk premium goes up, as well as the cost of capital. It is important to note that this does not mean investors are worse off. Aggregate prices will generally increase, and investors will achieve higher expected utilities.

\subsection{Information and Investment Decisions}

In the analysis above, the quality of the reporting system does not affect the "gross cash flow" generated by the firm. Implicitly, this means that the quality of the accounting system does not lead to a change in the manager's production or investment decisions. There are reasons to suspect that a change in the quality of the accounting system has an impact on the

\footnotetext{
${ }^{19}$ We thank the anonymous referee for pointing this out to us.
} 
firm's real decisions. For example, if the accounting system affects the firm's cost of capital (for the reasons discussed in the previous section), the optimal marginal investment changes. This happens even in the absence of any concerns about agency problems.

To provide a simple example, assume the manager decides on a production or investment quantity, $\mathrm{k}$, based on information he has about the profitability of the investment. The end-ofperiod cash flow is quadratic in the amount produced (invested): $\tilde{V}_{j}=k \tilde{\pi}_{j}-.5 k^{2}$, where the marginal productivity of investment, $\tilde{\pi}_{j}$, is uncertain at the time the investment is made. The manager observes a signal z before he makes his decision. This signal (which could constitute a report or a forecast) is also disclosed subsequently to investors. ${ }^{20}$ We assume that $\tilde{\pi}_{j}$ is normally distributed conditional upon the signal z, which implies that the cash flow distribution satisfies:

$$
\begin{aligned}
& E\left(\tilde{V}_{j} \mid z\right)=k(z) E(\tilde{\pi} \mid z)-.5 k^{2}(z) ; \\
& \operatorname{Var}\left(\tilde{V}_{j} \mid z\right)=k^{2}(z) \operatorname{Var}\left(\tilde{\pi}_{j} \mid z\right) ; \text { and } \\
& \operatorname{Cov}\left(\tilde{V}_{j}, \sum_{k \neq j} \tilde{V}_{k} \mid z\right)=k(z) \operatorname{Cov}\left(\tilde{\pi}_{j}, \sum_{k \neq j} \tilde{V}_{k} \mid z\right) .
\end{aligned}
$$

Note that both the variance of firm j's cash flow and the covariance of its cash flows with other firms are increasing in $\mathrm{k}$ (assuming the covariance is positive).

Next, we abstract from agency considerations and assume that, to align the interests of the manager with that of investors, the manager maximizes share price. That is, the manager chooses the investment level $k(z)$ to maximize the beginning-of-the-period price of the firm. Using eqn. (3), his objective function becomes

\footnotetext{
${ }^{20}$ We can vary how much information the manager has relative to investors without changing the qualitative nature of the result.
} 


$$
\begin{aligned}
\underset{\mathrm{k}(\mathrm{z})}{\operatorname{Maximize}} & \frac{1}{1+\mathrm{R}_{\mathrm{f}}}\left[\mathrm{E}\left(\tilde{\mathrm{V}}_{\mathrm{j}} \mid \mathrm{z}\right)-\frac{1}{\mathrm{~N} \tau}\left[\operatorname{Cov}\left(\tilde{\mathrm{V}}_{\mathrm{j}}, \sum_{\mathrm{k}=1}^{\mathrm{J}} \tilde{\mathrm{V}}_{\mathrm{k}} \mid \mathrm{z}\right)\right]\right] \\
= & \frac{k(\mathrm{z}) E(\tilde{\pi} \mid r)-.5 k^{2}(\mathrm{z})-\frac{1}{N \tau}\left\{k^{2}(z) \operatorname{Var}\left(\tilde{\pi}_{j} \mid z\right)+k(z) \operatorname{Cov}\left(\tilde{\pi}_{j}, \sum_{k \neq j} \tilde{V}_{k} \mid z\right)\right.}{1+R_{f}} .
\end{aligned}
$$

The optimal investment level then becomes

$$
k *(z)=\frac{E(\tilde{\pi} \mid r)-\frac{1}{N \tau} \operatorname{Cov}\left(\tilde{\pi}_{j}, \sum_{k \neq j} \tilde{V}_{k} \mid z\right)}{1+\frac{2}{N \tau} \operatorname{Var}\left(\tilde{\pi}_{j} \mid z\right)} .
$$

From the previous section, as the quality of information improves, the conditional variance and the conditional covariances decrease. Other things equal, this lowers the cost of capital. Eqn. (7) shows, however, that this also causes the manager to become more aggressive in his investment choice. This increase in $k^{*}(z)$, in turn, increases the variance and covariances, which increases the cost of capital. The equilibrium is then the net of these two effects. In our example, the overall effect decreases the cost of capital. ${ }^{21}$

In essence, this example captures the notion that share markets play a role in allocating capital and directing firms' investment choices (e.g., Tobin, 1982). Given this function, information quality is important because it affects the market's ability to direct firms’ capital allocation choices. As a consequence, information quality changes firms' future cash flows, not just the perceptions of these cash flows by market participants. Stated somewhat differently, higher information quality improves the coordination between firms and investors with respect to capital investment decisions. Anticipating this effect, investors demand a lower risk premium at the outset and discount the expected cash flows of firms with higher information quality at a

\footnotetext{
${ }^{21}$ It would be interesting to examine more general investment / production decision settings to see whether there are conditions under with the "indirect" effect dominates the "direct effect" so that an increase in the quality of the firm's accounting system actually increases the firm's cost of capital, rather than decreases it.
} 
lower rate of return. In short, investors price the risk of misalignment or misallocation that stems from poor information quality.

When there are agency problems between firms and managers, the quality of the firm's accounting and information system also affects the magnitude of these agency problems, and further changes the equilibrium production and investment decisions. Obviously, this involves modeling and analyzing the incentive mechanisms used to motivate the manager and monitor his decision. We leave this to future research to explore. It would be particularly interesting to examine the interaction between firm-specific factors and cost of capital in such a setting. For example, Christensen et al. (2002) examines how “idiosyncratic” risk affects managers’ investment decisions, and how compensation schemes should consider idiosyncratic and nondiversifiable risks. Future research could explore how the cost of capital charged to managers via compensation schemes influences their investment choices, and how this then affects the cost of capital to shareholders.

As the discussion above suggests, a change in accounting and disclosure systems affects the variances and covariances both directly and indirectly through real decisions. When a change leads to a shift in both the expected value and the covariances, the overall impact on cost of capital can be signed when the effects are reinforcing: that is, when expected cash flow and the overall covariance with all firms' cash flows move in opposite directions. When these two factors move in the same direction, however, we cannot sign the overall impact without placing more structure on the analysis. For example, we can sign the overall impact on the cost of capital as long as the expected value does not change "too much." We formalize this notion in the next proposition. 
Proposition 4. Let $\mu$ denote the expected cash flows and $\sigma$ denote the covariance of the firm's cash flows with those of the market given an information system and the decision that results from that information system. Let $\mu^{\prime}$ be the change in $\mu$ that accompanies the change in $\sigma$. Then the overall impact of a change in $\sigma$ on the firm's cost of capital has the same sign as the term, $\frac{\mu}{\sigma}-\mu^{\prime}$

For example, an increase in $\sigma$ without any increase in $\mu$ results in an increase in the firm's cost of capital, just as in Proposition 1. Similarly, if $\sigma$ increases while $\mu$ decreases, these effects reinforce each other, and the cost of capital increases. When $\sigma$ and $\mu$ change in the same direction, Proposition 4 places a bound on the extent of the impact on $\mu$. In particular, the impact on $\mu$ cannot exceed the ratio of the mean to the covariance. Note that this ratio can also be interpreted as the inverse of a measure analogous to the coefficient of variation of the cash flows, except it is the contribution of the firm to the overall variance of the market, not its own variance per se that is relevant.

An alternative way to state the condition in Proposition 4 is that the overall impact of a change in $\sigma$ on the cost of capital is positive (negative) if $\frac{d}{d \sigma} \ln \left[\frac{\mu}{\sigma}\right]$ is less than (greater than) zero. For example, suppose that the expected value is related to the covariance through the following functional form: $\mu=\sqrt{\psi_{0}+\psi_{1} \sigma}$, where $\psi_{0}$ and $\psi_{1}$ are arbitrary positive constants. Then we can use Proposition 4 to show that an increase in $\sigma$ leads to an increase in the cost of capital, whereas a decrease in $\sigma$ results in a decrease in the cost of capital.

\section{Conclusion}


In this paper, we develop a framework that links the disclosure of accounting information to the cost of capital. Specifically, we examine whether and how the quality of a firm's accounting information manifests in its cost of capital, despite the forces of diversification. We build a model of a multi-security economy that is consistent with the CAPM, but expressed in terms of cash flows, rather than returns. We augment this model with an information structure where accounting information and firms’ disclosure policies are represented as noisy signals about firms’ future cash flows.

Using this framework, we demonstrate that the quality of accounting information influences a firm's cost of capital, both directly by changing market participants' perceptions about the distribution of future cash flows, and indirectly by affecting real decisions that alter the distribution of future cash flows. The direct effect occurs because higher quality disclosures reduce a firm's assessed covariances with other firms' cash flows. This effect is not diversifiable in large economies. Our finding provides a direct link between the quality of a firm's disclosures and accounting policies and its cost of capital. In addition, it extends prior work in the estimation risk literature.

Our result that accounting information can lower a firm's cost of capital contrasts with contemporaneous work by Hughes et al. (2005). This paper only analyzes the direct effect of information, and concludes that only the market-wide risk premium changes; information has no cross-sectional effect. One reason for the apparent stark contrast to our results is the different definition of cost of capital. In particular, Hughes et al. define cost of capital as the difference between beginning-of-period price and end-of-period expected cash flows, whereas we use the more conventional definition of the expected rate of return on the firm's stock. Once we translate results from Hughes et al. into our definition of cost of capital, cross-sectional effects 
on cost of capital manifest. The nature of the cross-sectional effects differs from ours, however, due to the differences in the information structures assumed. Moreover, if indirect effects such as those we consider were introduced into Hughes et al. there would be additional cross-sectional differences in the effect of information on the cost of capital.

The indirect effect occurs because higher quality disclosures change a firm’s real decisions. As a consequence, the ratio of a firm's expected future cash flows to the covariance of these cash flows with the sum of the cash flows of all firms changes. This ratio is a key determinant of a firm's cost of capital. We show the indirect effect can go in either direction, but also derive conditions under which an increase in information quality leads to an unambiguous decline in the cost of capital.

The direct and indirect effects that we discuss are entirely consistent with the CAPM. In fact, the effects are captured by a fully-specified, forward-looking beta. If such a beta were available, there would be no theoretical justification in our model for including other variables in an empirical equation that attempts to explain or predict a firm's cost of capital. It is important to note, however, that this statement only holds if such a forward-looking beta is available. Betas derived from historical returns will generally not accomplish this. Therefore, proxies for the information effects outlined in this paper can be justified theoretically on the basis that they provide better estimates for forward-looking betas. But this justification is different from one where additional variables are included in the empirical specification to capture an "information risk” factor outside the one-factor CAPM.

Finally, we briefly comment on the impact of mandated disclosures or accounting policies on firms' cost of capital. Based on our model, it is easy to show that increasing the quality of mandated disclosures reduces the cost of capital for each firm in the economy 
(assuming that the expected cash flow of each firm and the covariance of that firm's cash flow with the market have the same sign). Nonetheless, disclosure regulation is likely to affect firms' assessed covariances with other firms differentially; hence, the benefits of mandatory disclosures are likely to differ across firms. For example, mandated disclosure may reduce the covariance of one firm's cash flows with the sum of the cash flows of all firms faster than for other firms.

Because mandated disclosure impacts the covariances of all firms with each other, a significant portion of its impact on the cost of capital of firms will occur through lowering the market risk premium. The effect of mandated disclosure on firms' beta factors is more difficult to predict. In particular, mandated disclosure cannot lower the beta coefficients of all firms because beta coefficients measure relative risk, and hence must aggregate to 1.0 regardless of the information set available to investors. The betas of those firms whose covariances of cash flows with the sum of the cash flows of all firms decrease relatively faster are likely to fall, while those whose covariances decrease relatively slower are likely to rise. Therefore, while mandated disclosure results in each firm having a lower cost of capital, its impact on betas is ambiguous. 


\section{APPENDIX}

\section{Proof of equation (3)}

Consider an economy with $J$ firms, indexed by the subscript $j=1,2, \ldots, J$, and a riskfree bond. We assume that the risk-free rate of return is $R_{f}$; that is, an investment of $\$ 1$ in the risk-free bond yields a return of $\$ 1+R_{f}$. Let $\tilde{V}_{j}$ and $P_{j}$ represent the uncertain cash flows of firm $j$ and the market equilibrium price of firm $j$, respectively. Along with the $J$ firms, we introduce a perfectly competitive market for firm shares comprised of $N$ investors, indexed by the subscript $i=1,2, \ldots, N$, where $N$ is large. We represent investors (homogeneous) knowledge about firms' cash flows by $\Phi$.

Let $U(c)$ represent investor $i$ 's utility preference for an amount of cash $c$. Each investor has a negative exponential utility function: that is, $U(c)$ is defined by

$$
U(c)=\tau\left(1-\exp \left[-\frac{1}{\tau} c\right]\right),
$$

where $\tau>0$ describes each investor's (constant) tolerance for risk. Note that this characterization of the negative exponential has the feature that as risk tolerance becomes unbounded, $U(c)$ converges asymptotically to risk neutrality:

$$
\lim _{\tau \rightarrow \infty} U(c)=\lim _{\tau \rightarrow \infty} \tau\left(1-\exp \left[-\frac{1}{\tau} c\right]\right) \rightarrow c .
$$

In addition, $U(\cdot)$ is standardized such that $U(0)=0$.

Now consider the market price for firm $j$ that prevails in a perfectly competitive market in which $N$ investors compete to hold shares in each firm, as well as a risk-free bond. Let $\bar{D}_{i}=\left\{D_{i 1}, D_{i 2}, \ldots, D_{i j}, \ldots, D_{i J}\right\}$ represent the $1 \times J$ vector of investor $i$ 's demand for ownership in $J$ firms, where $D_{i j}$ represents investor $i$ 's demand for firm $j$ expressed as percentage of the total firm; let $\bar{D}_{i}^{*}=\left\{D_{i 1}^{*}, D_{i 2}^{*}, \ldots, D_{i j}^{*}, \ldots, D_{i J}^{*}\right\}$ represent 
her vector of endowed ownership in firms, where $D_{i j}^{*}$ represents her endowment in firm $j$ expressed as a percentage of the total firm; and let $\bar{P}=\left\{P_{1}, P_{2}, \ldots, P_{j}, \ldots, P_{J}\right\}$ represent the vector of firm prices, where once again $P_{j}$ represents the price of firm $j$. Let $B_{i}$ and $B_{i}^{*}$ represent investor $i$ 's demand for a risk-free bond and her endowment in bonds, respectively. Each investor solves

$$
\max _{\bar{D}_{i}, B_{i}} E\left[\tau\left(1-\exp \left[-\frac{1}{\tau}\left(\bar{D}_{i}\left\{\tilde{V}_{1}, \tilde{V}_{2}, \ldots, \tilde{V}_{J}\right\}^{\prime}+\left(1+R_{f}\right) B_{i}\right)\right]\right) \mid \Phi\right]
$$

subject to the budget constraint

$$
\bar{D}_{i} \bar{P}^{\prime}+B_{i}=\bar{D}_{i}^{*} \bar{P}^{\prime}+B_{i}^{*}
$$

Taking the expectation of eqn. (A1) and substituting in the relation $B_{i}=\bar{D}_{i}^{*} \bar{P}^{\prime}+$ $B_{i}^{*}-\bar{D}_{i} \bar{P}^{\prime}$ yields the following expression

$$
\begin{aligned}
& \max _{\bar{D}_{i}, B_{i}} \tau\left(1-\exp \left[-\frac{1}{\tau}\left(\overline { D } _ { i } \left\{E\left[\tilde{V}_{1} \mid \Phi\right]-\left(1+R_{f}\right) P_{1},\right.\right.\right.\right. \\
& \left.\quad E\left[\tilde{V}_{2} \mid \Phi\right]-\left(1+R_{f}\right) P_{2}, \ldots, E\left[\tilde{V}_{J} \mid \Phi\right]-\left(1+R_{f}\right) P_{J}\right\}^{\prime} \\
& \left.\left.\left.\quad+\left(1+R_{f}\right) \bar{D}_{i}^{*} \bar{P}^{\prime}+\left(1+R_{f}\right) B_{i}^{*}\right)+\frac{1}{2} \frac{1}{\tau^{2}} \bar{D}_{i} \Lambda \bar{D}_{i}^{\prime}\right]\right),
\end{aligned}
$$

where $\Lambda$ is an $J \times J$ covariance matrix whose $s, t$-th term is $\operatorname{Cov}\left[\tilde{V}_{s} \cdot \tilde{V}_{t} \mid \Phi\right]$.

The first-order condition that maximizes eqn. (A2) with respect to $D_{i j}$ reduces to

$$
0=E\left[\tilde{V}_{j} \mid \Phi\right]-\left(1+R_{f}\right) P_{j}-\frac{1}{\tau} \sum_{k=1}^{J} D_{i k} \operatorname{Cov}\left[\tilde{V}_{j} \cdot \tilde{V}_{k} \mid \Phi\right] .
$$

Because collectively investors have claims to the cash flows of the entire firm, for each $k$ it must be the case that $\sum_{i=1}^{N} D_{i k}=1$. Thus, summing over both sides of eqn. (A3) with respect to $i$ yields

$$
0=N\left(E\left[\tilde{V}_{j} \mid \Phi\right]-\left(1+R_{f}\right) P_{j}\right)-\frac{1}{\tau} \sum_{i=1}^{N} \sum_{k=1}^{J} D_{i k} \operatorname{Cov}\left[\tilde{V}_{j} \cdot \tilde{V}_{k} \mid \Phi\right]
$$


or

$$
0=N\left(E\left[\tilde{V}_{j} \mid \Phi\right]-\left(1+R_{f}\right) P_{j}\right)-\frac{1}{\tau} \sum_{k=1}^{J} \operatorname{Cov}\left[\tilde{V}_{j} \cdot \tilde{V}_{k} \mid \Phi\right] .
$$

This, in turn, implies that the price for firm $j$ is given by

$$
P_{j}=\frac{E\left[\tilde{V}_{j} \mid \Phi\right]-\frac{1}{N \tau} \operatorname{Cov}\left[\tilde{V}_{j} \cdot \sum_{k=1}^{J} \tilde{V}_{k} \mid \Phi\right]}{1+R_{f}} .
$$

\section{Proof of Proposition 1}

From Lemma 1,

$$
E\left[\tilde{R}_{j}\right]=E\left[\frac{R_{f} H+1}{H-1}\right]
$$

where

$$
H=\frac{N \tau E\left[\tilde{V}_{j}\right]}{\operatorname{Cov}\left[\tilde{V}_{j}, \sum_{k=1}^{J} \tilde{V}_{k}\right]}
$$

When

$$
E\left[\tilde{V}_{j}\right]>0 \text { and } \operatorname{Cov}\left[\tilde{V}_{j}, \sum_{k=1}^{J} \tilde{V}_{k}\right]>0
$$

$H$ is increasing in both $E\left[\tilde{V}_{j}\right]$ and $N \tau$, and decreasing in $\operatorname{Cov}\left[\tilde{V}_{j}, \sum_{k=1}^{J} \tilde{V}_{k}\right]$. Note also that the derivative of $E\left[\tilde{R}_{j}\right]$ with respect to $H$ is negative:

$$
\begin{aligned}
\frac{\partial E\left[\tilde{R}_{j}\right]}{\partial H} & =\frac{(H-1) R_{f}-\left(R_{f} H+1\right)}{(H-1)^{2}} \\
& =\frac{H R_{f}-R_{f}-R_{f} H-1}{(H-1)^{2}} \\
& =-\frac{1+R_{f}}{(H-1)^{2}}<0 .
\end{aligned}
$$

Combining these, we have: $E\left[\tilde{R}_{j}\right]$ is decreasing in both $E\left[\tilde{V}_{j}\right]$ and $N \tau$, and increasing in $\operatorname{Cov}\left[\tilde{V}_{j}, \sum_{k=1}^{J} \tilde{V}_{k}\right]$. Finally, provided that $H>1$, which is necessary for $P_{j}>0$, we have $E\left[\tilde{R}_{j}\right]$ is increasing in $R_{f}$. Q.E.D. 


\section{Proof of Proposition 2}

We assume that $\tilde{V}_{j}, \tilde{V}_{k}, \tilde{\varepsilon}_{j}$, and $\tilde{\varepsilon}_{k}$ each have a normal distribution and define $\tilde{Z}_{j}$ and $\tilde{Z}_{k}$ as $\tilde{Z}_{j}=\tilde{V}_{j}+\tilde{\varepsilon}_{j}$ and $\tilde{Z}_{k}=\tilde{V}_{k}+\tilde{\varepsilon}_{k}$. Our only additional distributional assumption is that $\tilde{V}_{j}$ and $\tilde{V}_{k}$ are independent of $\tilde{\varepsilon}_{j}$ and $\tilde{\varepsilon}_{k}$, but not of each other. Taken together, these assumptions imply that $\tilde{V}_{j}, \tilde{V}_{k}, \tilde{Z}_{j}$, and $\tilde{Z}_{k}$ have a 4 -variate normal distribution with an unconditional covariance matrix given by

$$
M=\left[\begin{array}{llll}
\operatorname{Var}\left[\tilde{V}_{j}\right] & \operatorname{Cov}\left[\tilde{V}_{j}, \tilde{V}_{k}\right] & \operatorname{Var}\left[\tilde{V}_{j}\right] & \operatorname{Cov}\left[\tilde{V}_{j}, \tilde{V}_{k}\right] \\
\operatorname{Cov}\left[\tilde{V}_{j}, \tilde{V}_{k}\right] & \operatorname{Var}\left[\tilde{V}_{k}\right] & \operatorname{Cov}\left[\tilde{V}_{j}, \tilde{V}_{k}\right] & \operatorname{Var}\left[\tilde{V}_{k}\right] \\
\operatorname{Var}\left[\tilde{V}_{j}\right] & \operatorname{Cov}\left[\tilde{V}_{j}, \tilde{V}_{k}\right] & \operatorname{Var}\left[\tilde{V}_{j}\right]+\operatorname{Var}\left[\tilde{\varepsilon}_{j}\right] & \operatorname{Cov}\left[\tilde{V}_{j}, \tilde{V}_{k}\right]+\operatorname{Cov}\left[\tilde{\varepsilon}_{j}, \tilde{\varepsilon}_{k}\right] \\
\operatorname{Cov}\left[\tilde{V}_{j}, \tilde{V}_{k}\right] & \operatorname{Var}\left[\tilde{V}_{k}\right] & \operatorname{Cov}\left[\tilde{V}_{j}, \tilde{V}_{k}\right]+\operatorname{Cov}\left[\tilde{\varepsilon}_{j}, \tilde{\varepsilon}_{k}\right] & \operatorname{Var}\left[\tilde{V}_{k}\right]+\operatorname{Var}\left[\tilde{\varepsilon}_{k}\right]
\end{array}\right] .
$$

Simplify the covariance matrix notationally by setting: $\operatorname{V}=\operatorname{Var}\left[\tilde{V}_{j}\right] ; U=\operatorname{Var}\left[\tilde{V}_{k}\right]$; $C=\operatorname{Cov}\left[\tilde{V}_{j}, \tilde{V}_{k}\right] ; e=\operatorname{Var}\left[\tilde{\varepsilon}_{j}\right] ; f=\operatorname{Var}\left[\tilde{\varepsilon}_{k}\right] ;$ and $c=\operatorname{Cov}\left[\tilde{\varepsilon}_{j}, \tilde{\varepsilon}_{k}\right]$. This implies

$$
M=\left[\begin{array}{llll}
V & C & V & C \\
C & U & C & U \\
V & C & V+e & C+c \\
C & U & C+c & U+f
\end{array}\right] .
$$

The inverse of $M$ is

$$
M^{-1}=\left[\begin{array}{cccc}
\frac{U V f+U e f-U c^{2}-C^{2} f}{V U e f-V U c^{2}-C^{2} e f+C^{2} c^{2}} & -\frac{C e f-C^{2} c-C c^{2}+U V c}{V U e f-V U c^{2}-C^{2} e f+C^{2} c^{2}} & -\frac{f}{e f-c^{2}} & \frac{c}{e f-c^{2}} \\
-\frac{C e f-C^{2} c-C c^{2}+U V c}{V U e f-V U c^{2}-C^{2} e f+C^{2} c^{2}} & \frac{V e U+V e f-V c^{2}-C^{2} e}{V U e f-V U c^{2}-C^{2} e f+C^{2} c^{2}} & \frac{c}{e f-c^{2}} & -\frac{e}{e f-c^{2}} \\
-\frac{f}{e f-c^{2}} & \frac{c}{e f-c^{2}} & \frac{f}{e f-c^{2}} & -\frac{c}{e f-c^{2}} \\
\frac{c}{e f-c^{2}} & -\frac{e}{e f-c^{2}} & -\frac{c}{e f-c^{2}} & \frac{e}{e f-c^{2}}
\end{array}\right] .
$$

Let $m$ describe the submatrix

$$
m=\left[\begin{array}{cc}
\frac{U V f+U e f-U c^{2}-C^{2} f}{V U e f-V U c^{2}-C^{2} e f+C^{2} c^{2}} & -\frac{C e f-C^{2} c-C c^{2}+U V c}{V U e f-V U c^{2}-C^{2} e f+C^{2} c^{2}} \\
-\frac{C e f-C^{2} c-C c^{2}+U V c}{V U e f-V U c^{2}-C^{2} e f+C^{2} c^{2}} & \frac{V e U+V e f-V c^{2}-C^{2} e}{V U e f-V U c^{2}-C^{2} e f+C^{2} c^{2}}
\end{array}\right] .
$$


Then the covariance matrix for $\tilde{V}_{j}$ and $\tilde{V}_{k}$ conditional on $\tilde{Z}_{j}$ and $\tilde{Z}_{k}$ is given by

$$
m^{-1}=\left[\begin{array}{cc}
\frac{V e U+V e f-V c^{2}-C^{2} e}{V U+V f+e U+e f-(C+c)^{2}} & \frac{U V c+C e f-C c(C+c)}{V U+V f+e U+e f-(C+c)^{2}} \\
\frac{U V c+C e f-C c(C+c)}{V U+V f+e U+e f-(C+c)^{2}} & \frac{U V f+U e f-U c^{2}-C^{2} f}{V U+V f+e U+e f-(C+c)^{2}}
\end{array}\right] .
$$

The off-diagonal terms in $m^{-1}$ describe $\operatorname{Cov}\left[\tilde{V}_{j}, \tilde{V}_{k} \mid Z_{j}, Z_{k}\right]$; converting this expression back into non-simplified expressions yields

$$
\begin{array}{r}
\operatorname{Var}\left[\tilde{V}_{k}\right] \operatorname{Var}\left[\tilde{V}_{j}\right] \operatorname{Cov}\left[\tilde{\varepsilon}_{j}, \tilde{\varepsilon}_{k}\right]+\operatorname{Cov}\left[\tilde{V}_{j}, \tilde{V}_{k}\right] \operatorname{Var}\left[\tilde{\varepsilon}_{j}\right] \operatorname{Var}\left[\tilde{\varepsilon}_{k}\right] \\
\operatorname{Cov}\left[\tilde{V}_{j}, \tilde{V}_{k} \mid Z_{j}, Z_{k}\right]=\frac{-\operatorname{Cov}\left[\tilde{V}_{j}, \tilde{V}_{k}\right] \operatorname{Cov}\left[\tilde{\varepsilon}_{j}, \tilde{\varepsilon}_{k}\right]\left(\operatorname{Cov}\left[\tilde{V}_{j}, \tilde{V}_{k}\right]+\operatorname{Cov}\left[\tilde{\varepsilon}_{j}, \tilde{\varepsilon}_{k}\right]\right)}{\operatorname{Var}\left[\tilde{Z}_{j}\right] \operatorname{Var}\left[\tilde{Z}_{k}\right]-\left(\operatorname{Cov}\left[\tilde{V}_{j}, \tilde{V}_{k}\right]+\operatorname{Cov}\left[\tilde{\varepsilon}_{j}, \tilde{\varepsilon}_{k}\right]\right)^{2}},
\end{array}
$$

where $\operatorname{Var}\left[\tilde{Z}_{j}\right]=\operatorname{Var}\left[\tilde{V}_{j}\right]+\operatorname{Var}\left[\tilde{\varepsilon}_{j}\right]$ and $\operatorname{Var}\left[\tilde{Z}_{k}\right]=\operatorname{Var}\left[\tilde{V}_{k}\right]+\operatorname{Var}\left[\tilde{\varepsilon}_{k}\right]$. Now suppose that $\tilde{\varepsilon}_{j}$ and $\tilde{\varepsilon}_{k}$ are uncorrelated. Then this expression reduces further to

$$
\operatorname{Cov}\left[\tilde{V}_{j}, \tilde{V}_{k} \mid Z_{j}, Z_{k}\right]=\operatorname{Cov}\left[\tilde{V}_{j}, \tilde{V}_{k}\right] \frac{\operatorname{Var}\left[\tilde{\varepsilon}_{j}\right] \operatorname{Var}\left[\tilde{\varepsilon}_{k}\right]}{\operatorname{Var}\left[\tilde{Z}_{j}\right] \operatorname{Var}\left[\tilde{Z}_{k}\right]-\left(\operatorname{Cov}\left[\tilde{V}_{j}, \tilde{V}_{k}\right]\right)^{2}}
$$

Finally, $\operatorname{Cov}\left[\tilde{V}_{j}, \tilde{V}_{k} \mid Z_{j}\right]$ can be derived from the expression for $\operatorname{Cov}\left[\tilde{V}_{j}, \tilde{V}_{k} \mid Z_{j}, Z_{k}\right]$ by assuming that $\operatorname{Var}\left[\tilde{\varepsilon}_{k}\right]$ becomes unboundedly large while $\operatorname{Var}\left[\tilde{V}_{k}\right]$ remains constant; note that this implies that $\operatorname{Var}\left[\tilde{Z}_{k}\right]$ becomes unboundedly large. In other words,

$$
\begin{aligned}
\operatorname{Cov}\left[\tilde{V}_{j}, \tilde{V}_{k} \mid Z_{j}\right] & =\lim _{\operatorname{Var}\left[\tilde{\varepsilon}_{k}\right] \rightarrow \infty} \operatorname{Cov}\left[\tilde{V}_{j}, \tilde{V}_{k} \mid Z_{j}, Z_{k}\right] \\
& \rightarrow \operatorname{Cov}\left[\tilde{V}_{j}, \tilde{V}_{k}\right] \frac{\operatorname{Var}\left[\tilde{\varepsilon}_{j}\right]}{\operatorname{Var}\left[\tilde{Z}_{j}\right]}
\end{aligned}
$$

Q.E.D.

\section{Proof of Proposition 3}

The expected value and covariance of the net amount received by the firm's shareholders are

$$
E\left[\tilde{V}_{j} \mid Q\right]=\left(1-A_{1}(Q)\right) E\left[\tilde{V}_{j}^{*}\right]-A_{0}(Q)
$$


and

$\frac{1}{N \tau} \operatorname{Cov}\left[\tilde{V}_{j}, \sum_{k=1}^{J} \tilde{V}_{k} \mid Q\right]=\frac{1}{N \tau}\left(\left[1-A_{1}(Q)\right]^{2} \operatorname{Var}\left[V_{j}^{*}\right]+\left[1-A_{1}(Q)\right] \operatorname{Cov}\left[\tilde{V}_{j}, \sum_{k \neq j}^{J} \tilde{V}_{k} \mid Q\right]\right)$,

respectively. With a large number of firms, the firm-variance effect is small; thus, $H(Q)$ can be expressed as

$$
H(Q)=\frac{E\left[\tilde{V}_{j} \mid Q\right]}{\frac{1}{N \tau} \operatorname{Cov}\left[\tilde{V}_{j}, \sum_{k=1}^{J} \tilde{V}_{k} \mid Q\right]} \approx \frac{\left(1-A_{1}(Q)\right) E\left[\tilde{V}_{j}^{*}\right]-A_{0}(Q)}{\left(1-A_{1}(Q)\right) \operatorname{Cov}\left[\tilde{V}_{j}, \sum_{k \neq j}^{J} \tilde{V}_{k} \mid Q\right]} .
$$

Next, for convenience let $E^{*}$ and $C^{*}$ represent $E\left[\tilde{V}_{j}^{*}\right]$ and $\operatorname{Cov}\left[\tilde{V}_{j}, \sum_{k \neq j}^{J} \tilde{V}_{k} \mid Q\right]$, respectively. Then

$$
\begin{aligned}
\frac{\partial H}{\partial Q} & =\frac{\left(-A_{1}^{\prime}(Q) E^{*}-A_{0}^{\prime}(Q)\right)\left(1-A_{1}(Q)\right) C^{*}-\left(\left[1-A_{1}(Q)\right] E^{*}-A_{0}(Q)\right)\left(-A_{1}^{\prime}(Q) C^{*}\right)}{\left(\left[1-A_{1}(Q)\right] C^{*}\right)^{2}} \\
& =\frac{-A_{0}^{\prime}(Q)\left(1-A_{1}(Q)\right) C^{*}-A_{0}(Q) A_{1}^{\prime}(Q) C^{*}}{\left(\left[1-A_{1}(Q)\right] C^{*}\right)^{2}} \\
& =\frac{-A_{0}^{\prime}(Q)\left(1-A_{1}(Q)\right)-A_{0}(Q) A_{1}^{\prime}(Q)}{\left(1-A_{1}(Q)\right)^{2} C^{*}}
\end{aligned}
$$

Noting that $A_{0}^{\prime}(Q)$ and $A_{1}^{\prime}(Q)$ are both non-negative, provided that $C^{*}>0$ we have

$$
\frac{\partial H}{\partial Q} \geq 0
$$

with $\frac{\partial H}{\partial Q}=0$ if $A_{0}(Q)=A_{0}^{\prime}(Q)=0$. Finally, from Lemma 1 the cost of capital is decreasing in $H(Q)$. Q.E.D.

\section{Proof of Proposition 4}

Cost of capital is defined as

$$
E\left[\tilde{R}_{j} \mid \Phi\right]=\frac{R_{f} E\left[\tilde{V}_{j}|\Phi|\right]+\frac{1}{N \tau} \operatorname{Cov}\left[\tilde{V}_{j}, \sum_{k=1}^{J} \tilde{V}_{k}|\Phi|\right]}{E\left[\tilde{V}_{j}|\Phi|\right]-\frac{1}{N \tau} \operatorname{Cov}\left[\tilde{V}_{j}, \sum_{k=1}^{J} \tilde{V}_{k}|\Phi|\right]}
$$


Let $\sigma=\operatorname{Cov}\left[\tilde{V}_{j}, \sum_{k=1}^{J} \tilde{V}_{k}|\Phi|\right], \mu=E\left[\tilde{V}_{j}|\Phi|\right]$, and $\mu^{\prime}=\frac{d}{d \operatorname{Cov}\left[\tilde{V}_{j}, \sum_{k=1}^{J} \tilde{V}_{k}|\Phi|\right]} E\left[\tilde{V}_{j}|\Phi|\right]$. This allows $E\left[\tilde{R}_{j} \mid \Phi\right]$ to be defined as

$$
E\left[\tilde{R}_{j} \mid \Phi\right]=\frac{R_{f} \mu+\frac{1}{N \tau} \sigma}{\mu-\frac{1}{N \tau} \sigma}
$$

In addition,

$$
\begin{aligned}
\frac{d}{d \sigma} E\left[\tilde{R}_{j} \mid \Phi\right] & =\frac{\left(R_{f} \mu^{\prime}+\frac{1}{N \tau}\right)\left(\mu-\frac{1}{N \tau} \sigma\right)-\left(R_{f} \mu+\frac{1}{N \tau} \sigma\right)\left(\mu^{\prime}-\frac{1}{N \tau}\right)}{\left(\mu-\frac{1}{N \tau} \sigma\right)^{2}} \\
& =-\frac{\frac{1}{N \tau}\left(\sigma \mu^{\prime}-\mu\right)\left(R_{f}+1\right)}{\left(\mu-\frac{1}{N \tau} \sigma\right)^{2}} .
\end{aligned}
$$

This implies that $\frac{d}{d \sigma} E\left[\tilde{R}_{j} \mid \Phi\right]$ assumes the same sign as the sign of the change in $\sigma$ provided that

$$
\mu^{\prime}<\frac{\mu}{\sigma}
$$

In other words, a decrease in $\sigma$ implies a decrease in $E\left[\tilde{R}_{j} \mid \Phi\right]$, provided that $\mu^{\prime}<\frac{\mu}{\sigma}$. Q.E.D. 


\section{REFERENCES}

Admati, A., P. Pfleiderer, 2000, Forcing firms to talk: financial disclosure regulation and externalities, The Review of Financial Studies 13, 479-519.

Amihud, Y., H. Mendelson, 1986, Asset pricing and the bid-ask spread, Journal of Financial Economics 17, 223-249.

Baiman, S., R. Verrecchia, 1996, The relation among capital markets, financial disclosure, production efficiency, and insider trading, Journal of Accounting Research 34, 1-22.

Barry, C., S. Brown, 1984, Differential information and the small firm effect, Journal of Financial Economics 13, 283-294.

Barry, C., S. Brown, 1985, Differential information ad security market equilibrium, Journal of Financial and Quantitative Analysis 20, 407-422.

Beaver, W., P. Kettler, M. Scholes, 1970, The association between market-determined and accounting-determined measures of risk, The Accounting Review 45, 654-682.

Botosan, C., 1997, Disclosure level and the cost of equity capital, The Accounting Review 72, 323-349.

Botosan, C., M. Plumlee, 2002, A re-examination of disclosure level and the expected cost of equity capital, Journal of Accounting Research 40, 21-41.

Brown, S., 1979, The effect of estimation risk on capital market equilibrium, Journal of Financial and Quantitative Analysis 15, 215-220.

Chordia, T., R. Roll, A. Subrahmanyam, 2001, Market liquidity and trading activity, Journal of Finance 56, 501-530.

Christensen, P., G. Feltham, M. Wu, 2002, 'Cost of capital' in residual income for performance evaluation, The Accounting Review 77, 1-23.

Coles, J., U. Loewenstein, 1988, Equilibrium pricing and portfolio composition in the presence of uncertain parameters, Journal of Financial Economics 22, 279-303.

Coles, J., U. Loewenstein, J. Suay, 1995, On equilibrium pricing under parameter uncertainty, The Journal of Financial and Quantitative Analysis 30, 347-374.

Degroot, M , 1970, Optimal Statistical Decisions, Wiley and Sons, Hoboken NJ.

Diamond, D., R. Verrecchia, 1991, Disclosure, liquidity and the cost of capital, Journal of Finance 46, 1325-1359.

Easley, D., M. O’Hara, 2004, Information and the cost of capital, Journal of Finance 59, 15531583.

Easley, D., S. Hvidkjaer, M. O’Hara, 2002, Is information risk a determinant of asset returns? Journal of Finance 57, 2185-2222.

Fama, E., 1976, Foundations of Finance, Basic Books, New York.

Fama, E., M. Miller, 1972, The Theory of Finance, Dryden Press, Hinsdale IL. 
Fishman, M., K. Hagerty, 1989, Disclosure decisions by firms and the competition for price efficiency, Journal of Finance 44, 633-646.

Foster, G., 1981, Intra-industry information transfers associated with earnings releases, Journal of Accounting and Economics 3, 201-232.

Foster, N., 2003, The FASB and the capital markets, The FASB Report (June 2003).

Francis, J., R. LaFond, P. Olsson, K. Schipper, 2004, Costs of equity and earnings attributes, The Accounting Review 79, 967-1010.

Gebhardt, W., C. Lee, C., B. Swaninathan, 2001, Toward an implied cost of capital, Journal of Accounting Research 39, 135-176.

Hail, L., C. Leuz, 2006, International differences in the cost of equity capital: do legal institutions and securities regulation matter? Journal of Accounting Research 44, forthcoming.

Hughes, J., J. Liu, J. Liu, 2005, Information, diversification and the cost of capital, working paper, UCLA.

Kalymon, B., 1971, Estimation risk in the portfolio selection model, Journal of Financial and Quantitative Analysis 6, 559-582.

Kanodia, C., A. Mukherji, H. Sapra, R. Venugopalan, 2000, Hedge disclosures, future prices, and production distortions, Journal of Accounting Research 38, 53-83.

Kanodia, C., H. Sapra, R. Venugopalan, 2004, Should intangibles be measured: what are the economic trade-offs? Journal of Accounting Research 42, 89-120.

Lambert, R., 2001, Contracting theory and accounting, Journal of Accounting and Economics 32, 3-87.

LaPorta, R., Lopez-de-Silanes, F., Shleifer, A., R. Vishny, 1997, Legal determinants of external finance, Journal of Finance 52, 1131-1150.

Levitt, A., 1998, The importance of high quality accounting standards, Accounting Horizons 12, 79-82.

Lintner, J., 1965, The Valuation of risk assets and the selection of risky investments in stock portfolios and capital budgets, Review of Economics \& Statistics 65, 13-37.

Lombardo, D., M. Pagano, 2002, Law and equity markets: a simple model, CSEF Working Paper No. 25, and CEPR Discussion Paper No. 2276, in Corporate Governance Regimes: Convergence and Diversity, J. McCahery, P. Moerland, T. Raaijmakers and L. Renneboog (eds.), Oxford University Press, 343-362.

Merton, R., 1987, A simple model of capital market equilibrium with incomplete information, Journal of Finance 43, 483-510.

Pastor, L., R. Stambaugh, 2003, Liquidity risk and expected stock returns, Journal of Political Economy 111, 642-685.

Piotroski, J., D. Roulstone, 2004, The influence of analysts, institutional investors and insiders on the incorporation of market, industry and firm-specific information into stock prices, The Accounting Review 79, 1119-1151. 
Sharpe, W., 1964, Capital asset prices, a theory of market equilibrium under conditions of risk, Journal of Finance 19, 425-442.

Tobin, J., 1982, On the efficiency of the financial system, Lloyd's Banking Review 153, 1-15.

Verrecchia, R., 2001, Essays on disclosure, Journal of Accounting and Economics 32, 97-180. 